\title{
Thermal analysis of shell and tube heat exchangers using artificial neural networks
}

\author{
Ananth S. Iyengar \\ M.S.Ramaiah University of Applied Sciences \\ \#470-P, Peenya Industrial Area, Peenya 4th Phase, Bengaluru, Karnataka, India \\ Email: iyengar.ananth@gmail.com
}

\begin{abstract}
The shell and tube heat exchangers are most commonly used industrial equipment to transfer heat from one fluid to another. The design process is specified by Tubular Exchanger Manufacturers Association (TEMA). The initial design has to be iteratively optimized for increasing the heat transfer, minimize the pressure drop and reduce the fluid pumping power. LMTD method is chosen for its simplicity and quick analysis. The design procedure if approached by Finite element method, needs high computing power and tedious to converge. A feed-forward artificial neural network is set up to simplify the iterative nature of the design process. This also gives the necessary quick design iteration cycles to reach the optimized design. A design space is created with heat exchanger parameters, and the feed forward network is trained with semi-empirical data. The trained network is used in the design performance evaluation. This approach shows promise of quick design changes and can accommodate variable thermo-physical properties of fluids, and can be trained for different fouling patterns in the heat exchangers from real time data. The neural network can predict the steady state performance within the design space and results match well with LMTD calculations. Subsequent to the steady state analysis, dynamic modeling is attempted. A neural network method is used to reduce the complication of the model. Simplified mathematical model is used initially to train the network. It is found that the feed forward networks can predict the dynamic behavior, but it needs additional parameters to improve its predictions.
\end{abstract}

Keywords: Shell and tube heat exchanger, feed forward, artificial neural network

DOI: http://dx.doi.org/10.4314/ejst.v8i2.5

\section{INTRODUCTION}

Efficient transfer of heat between two non-mixing fluid streams is a basic requirement in many process industries. Heat exchangers are proven choice for heat transfer between liquids, gases and their multiphase mixtures. The heat exchangers also can be used either to condense a vapor stream or to vaporize a liquid stream. Among the various types of heat exchangers, shell and tube heat exchangers are the most commonly employed devices in industries. The thermal characteristics of such a heat exchanger depends on the tube side design, shell design, the thermo-physical properties of fluids, and the phase change during heat transfer if any. Tube design includes choice of tube dimensions and number, tube material, arrangement of tubes. The design parameters are chosen to accommodate the steady and unsteady heat transfer processes during the regular working of the heat exchanger. Other consideration during the initial design includes the fouling factor that tends to reduce the heat transfer rate between fluids.

There are two common methods of steady state heat exchanger design namely, Log Mean Temperature Difference (LMTD) method and Effectiveness - Number of Transfer Units ( $\varepsilon$-NTU) technique. LMTD method is an iterative process that involves recalculation of design steps to get the best overall design. Although LMTD method is simpler, it involves several challenges such as complicated geometries like finned tubes, fouling patterns and phase change. These complications can be simplified using some common assumptions in the shell and tube heat exchanger design: 


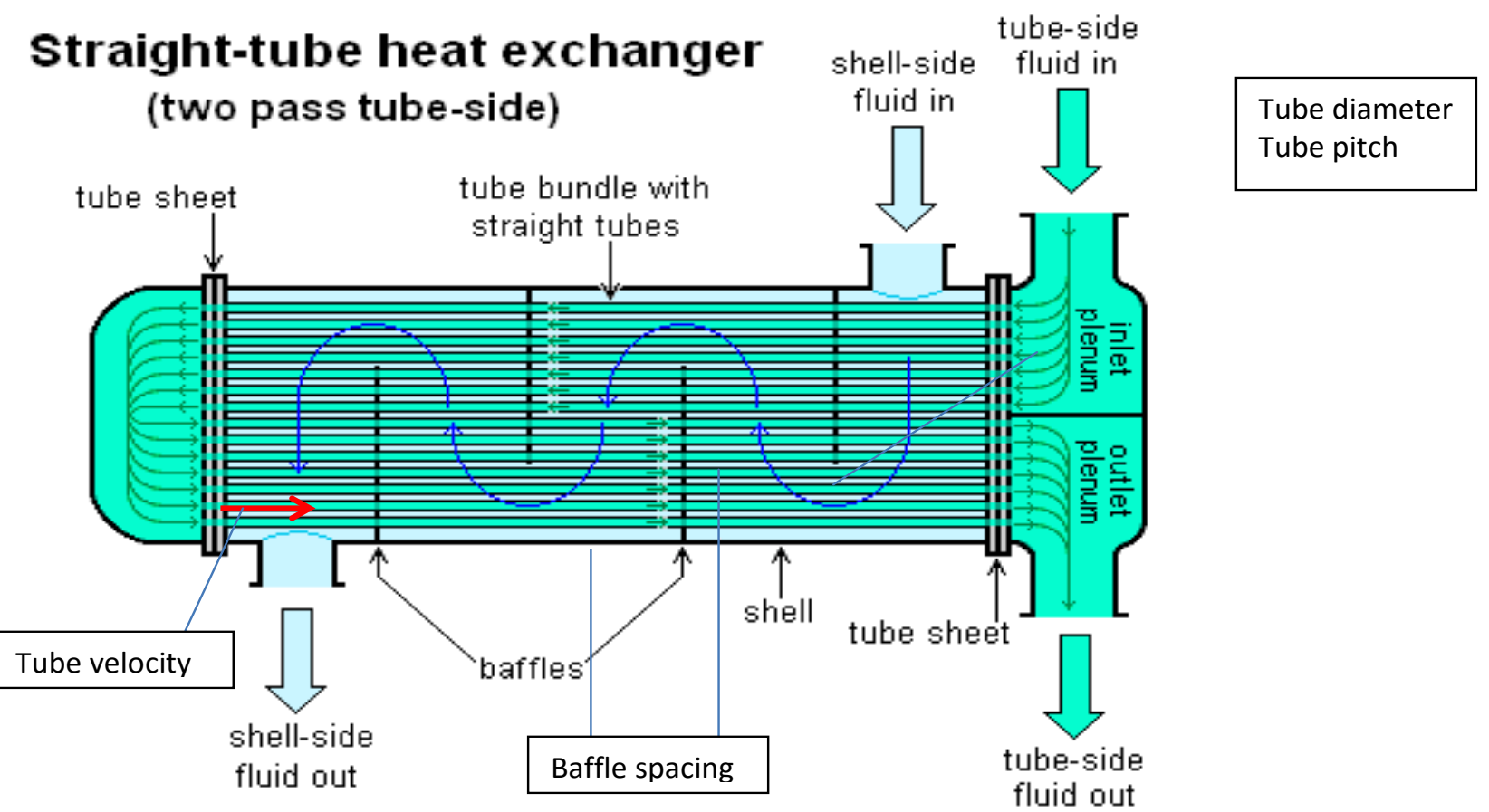

Figure 1. A two pass shell and tube heat exchanger (adapted from Wikipedia.org)

- constant thermo-physical fluid properties,

- semi-empirical correlations for complex flow patterns in the shell flow streams

- Negligible heat loss from the shell to environment

Accurate design optimization of heat exchangers is in particular more mathematically involved and time consuming process. A quick optimization routine that can be further improved to include the real-time data is needed. Artificial Neural Network (ANN) can be used for thermal design optimization of heat exchangers. This paper implements simple feed-forward -back-propagation technique to heat exchanger thermal design.

The aim of the thermal design of heat exchangers is to calculate the heat transfer area. The heat transfer area is the outer tube surface. This area can be calculated by the number of tubes, the tube diameters.
The heat transfer also is dependent on the shell parameters like shell diameter, tube spacing, length of heat exchanger. Figure 1 shows some of these parameters, and in this research we investigate the accuracy of artificial neural networks compared to the kern's method routinely used in the thermal design of heat exchangers.

\section{Artificial neural networks in thermal design}

The design and prediction of heat exchanger behavior are too complicated to mathematically model and solve using analytical solution. Closed form solutions are available only in situations where the model has several simplifying assumptions (Gvozdenac and Mitrovic, 2012). Heat exchanger design based on these assumptions has errors that make the prediction of thermal behavior challenging. The design challenges are multiple objectives with several constraints to be fulfilled simultaneously. Advanced mathematical techniques such as 
regression, simulated annealing, genetic algorithms and neural networks are being employed to solve these multi-objective design problems. Artificial Neural Networks (ANN) is a network of simple functional nodes that can correlate the inputs to the outputs for complicated mathematical model in most engineering situation. The heat exchanger performance calculation and control of dynamic behavior requires the temporal prediction of fluid properties, fluid flow behavior and surface properties of solid boundaries. The use of ANN either as a single network or network of networks can accomplish this as a 'black box' approach, with all the network constants and connections hidden from user. The recent increase in the use of ANN for thermal design is due to its simplicity and versatility.

ANN as a mathematical tool is employed in a variety of heat exchanger related solutions. It is used in thermal performance prediction for compact heat exchangers (Tan et al., 2003), performance of cross flow heat exchanger (Gerardo et al., 1999), dynamic prediction and control of heat exchanger (Wolff et al. 1991), dynamic prediction and control of heat exchanger networks (Gerardo et al., 2001), prediction of fouling factor (Riverol and Nepolitano 2005), heat rate prediction (Pacheco et al. 2001), prediction and control of non-linear heat exchanger process (Jalali et al., 2004; Vasičkaninováet al., 2011), heat exchanger functional control based on fuzzy model (Duran et al., 2008), and cost estimation of shell and tube heat exchangers (Costaa and Queiroz, 2008). ANN algorithms is used to minimize the thermal exchange surface (Ponce-Ortega et al., 2009), other researchers have reported the use of genetic algorithm in the design of shell-andtube heat exchanger (Selbaşet et al., 2006). In this paper, ANN is used to predict the heat exchanger steady state behavior after the conventional design process.

\section{Feed forward neural networks}

Feed forward neural network is one of the many available mathematical goal seeking or optimization programs. The mathematical setup consists of interconnected virtual or artificial neurons. In Figure 2 there are three columns of neurons. Towards the left there are four input neurons corresponding to the four input parameters chosen. The middle column is the hidden set neurons that can act as a combined function connecting the input neurons to output neurons. The output neurons are three in number showing the three design calculated values. All the neurons, input, hidden and output have a threshold value and a function associated with it. The connections between the artificial neurons depicted by arrows have weight associated with them. The Feed forward back propagation method will train the predetermined set of neurons and connections to have a particular value for the neuron threshold and weights of the connections. This training of network is based on the set of training data set provided to the ANN. The trained network now is capable of predicting the pattern in the input signals and provides the required outputs based on the patterns in the inputs. In the current research, the input data consists of velocity, baffle distance, pipe thickness and tube pitch. The set of output parameters are overall heat transfer coefficient, pressure drop in pipes and pressure drop in shell. Ideally the training data set is to be measured using data loggers from a working heat exchanger. But for this study, correlations in Kern's method are used for training set of data. The training data set consisted of 1080 data points. The ANN program was setup on a personal computer and it was possible to train the program for this moderate training data with the resources available. The trained data set was then used for intermediate values from the input parameter values and found to be good agreement. 


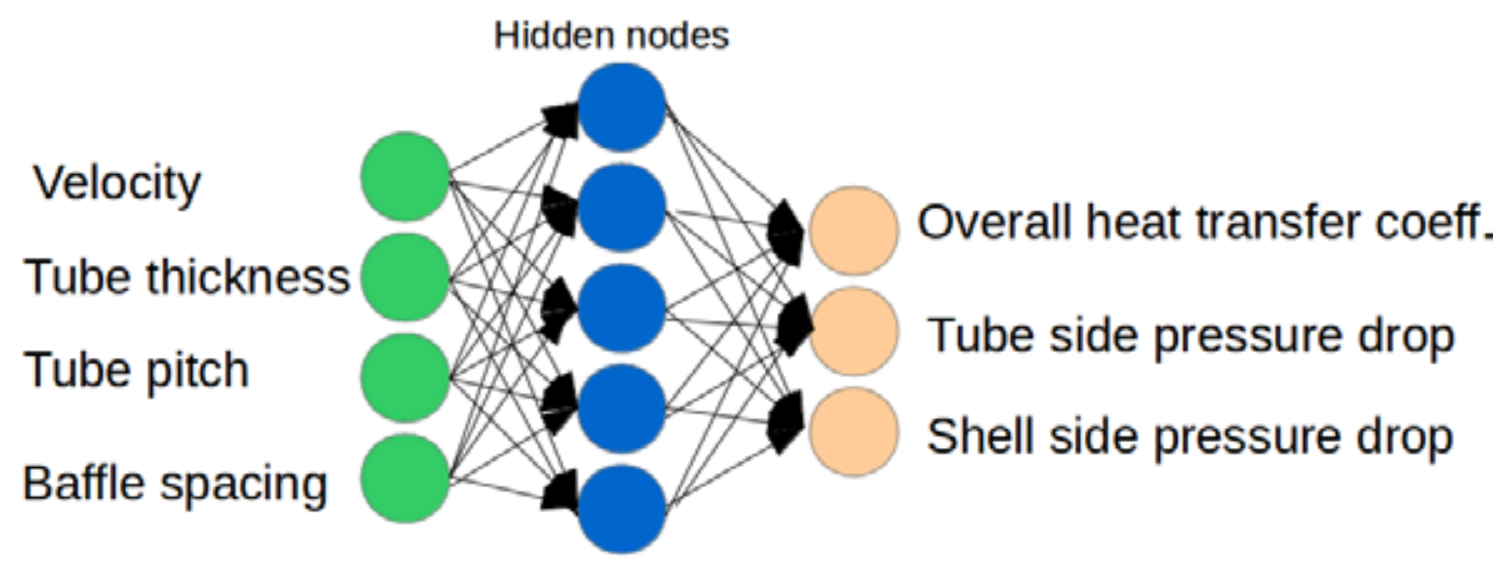

Figure 2. Schematic of a feed forward neural network

The project was implemented using a JAVA code titled ENCOG available under GPL license at Heaton Research. ENCOG contains several neural network codes including genetic algorithm, simulated annealing and feed forward network. The feed forward network code is given below that shows the scaled input vector and the function The actual JAVA program is given below, suitable comments are provided in the code snippet to show the steps in the ANN training and testing procedure.

packageorg.encog.examples.neural.xor;

public static double XOR IDEAL[] [] = $\{\{0.2553269181,0.8829513006,0.039737512$

$1\}$,

$2199421\}$

$9828444\}\}$

$\{0.3510574885,0.0176696858,0.001$

$\{0.3097410109,0.8288364047,0.081$

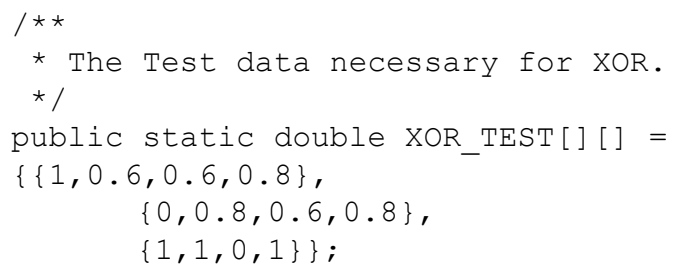

public static void main(final string $\operatorname{args}[]) \quad\{$

// create a neural network,

without using a factory

BasicNetwork network = new

BasicNetwork ()

// create input nodes

// created

// created 4 input nodes

(velocity, pipethickness, bafflespacing, tube pitch)

// created 6 hidden nodes

// created 3 output node (U

overall, Tube prdrop, Shellpr drop) network. addLayer (new

Basiclayer (null, true, 4));

// create hidden nodes network. addLayer (new

Basiclayer (new Activationsigmoid(), true, 6)); // create output nodes network. addLayer (new

Basiclayer(new Activationsigmoid(), false, 3)) ;

finalizestructure (); network. getstructure ().

network.reset ();

$\{\{1,0.6,0.6,0.8\}$

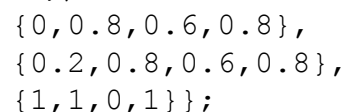


BasicMLDataSet(XOR_INPUT, XOR_IDEAL); MLDatasettestingset $=$ new BasicMLDataset (XOR_TEST, XOR_IDEAL);

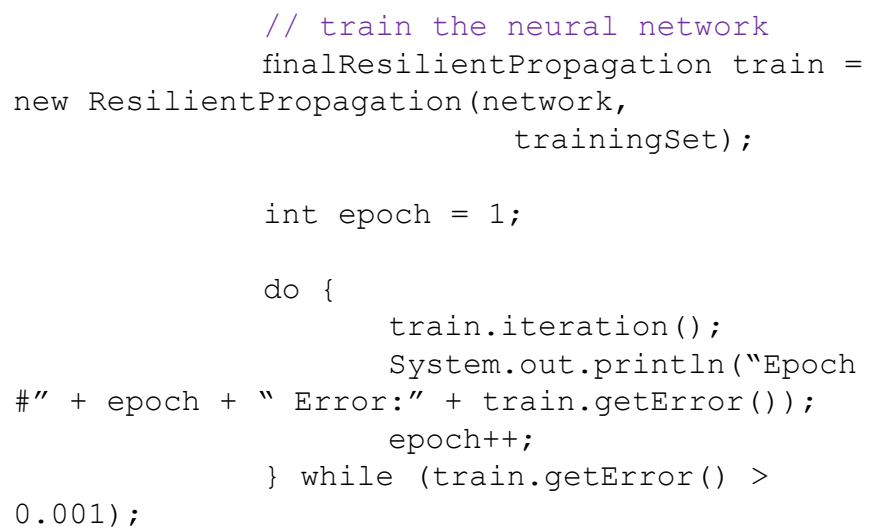

// test the neural network System.out.println("Epoch \#" +

\section{THERMAL DESIGN OF SHELL AND TUBE}

\section{HEAT EXCHANGER}

Heat exchanger design is extensively discussed in Kakac and the neural networks approach for the thermal system design is given in Jaluria. ANN being an advanced mathematical tool helps us quickly optimize the designs. The choices during the initial design have to satisfy the allowable pressure drop requirements. The shell design involves the baffle shape and number, shell clearances that accommodate the shell-side pressure drop and pumping power requirements. Thermal design based on LMTD method of shell and tube heat exchangers can be accomplished by two methods namely the Kern's method and the Bell Delaware method. The fundamental steps in both these methods remain the same with differences in the design calculations for shell side fluid flow. In the Kern's method, simple correlations are assumed for the shell side heat transfer and fluid flow. In reality the shell side fluid flow is more complicated due to the cross flow, baffle window flow, flow in the baffle-shell region, and bundle-shell bypass streams. Separate correlations are to be used to account for these complex flow patterns that affect the thermal characteristics of the designed heat exchanger. Bell - Delaware method is especially necessary in the case of two phase flow on the shell side flow. For this study the Kern's method is employed because the chosen problem from the literature (Rajiv, 1998) does not contain two phase flow. As it can be observed from the later sections of this paper, the choice of the method does not affect the results from the artificial neural network and Bell-Delaware technique can be easily incorporated into the thermal analysis without major modification to the overall design approach. The brief steps in Kern's method are given in the subsequent sections for completeness.

Several assumptions are made in the steady state analysis and transient analysis:

- In both steady state and transient analysis, no heat loss from the shell

- No phase change either in steady state or transient analysis

- Flow rate remains constant in both cases, temperature rise is imposed in the transient analysis

\section{Design problem from literature}

Table 1 shows the design parameters taken from one of the design case study from literature (Rajiv, 1998). 
Table 1. The specification of heat exchanger

\begin{tabular}{llll}
\hline Parameters & Shell side & Tube side & Units \\
\hline Fluid type & Crude oil & Heavy gas oil & --- \\
Flow rate & 77 & 111.064 & $\mathrm{~kg} / \mathrm{s}$ \\
Temperature(in/out) & $227 / 249$ & $302 / 275$ & ${ }^{\circ} \mathrm{C}$ \\
Operating pressure (abs) & 28.848 & 13.251 & $\mathrm{kPa}$ \\
Allowable pressure drop & 1.223 & 0.713 & $\mathrm{kPa}$ \\
Fouling resistance & 0.0006 & 0.0005 & $\mathrm{~s} \mathrm{~m} 2 \mathrm{~K} / \mathrm{J}$ \\
Viscosity & $0.664 / 0.563$ & $0.32 / 0.389$ & $\mathrm{centi}$ Poise \\
Design pressure & 44.852 & 17.329 & $\mathrm{kPa}$ \\
\hline
\end{tabular}

The data from the reference is converted to SI units and reproduced in table 1 for completeness. Since the aim of the present paper is the validation and checks the prediction capability of artificial neural networks, an already validated thermal design data sample was selected and the prediction from the ANN was compared to the existing design solutions.

The data for the ANN is prepared using design of experiments process for 4 input parameters namely, velocity of the fluid in the tubes, tube thickness, ratio of baffle spacing to shell diameter and ratio of tube pitch to tube outer diameter. The total discharge of fluid on the tube side remains constant, by having different velocity values, the number of tubes varies. This change in the number of tubes indicates the diameter of tubes change. All the above parameters were chosen because of their direct influence on the performance of the shell and tube heat exchangers. The values for the above 4 input parameters were first calculated from the design data available from the literature are given in table 1 . The outer diameter of the tubes is assumed to be $26 \times 10^{-3} \mathrm{~m}(26 \mathrm{~mm})$ and the inner diameter of the tubes is altered to get the desired thickness of tubes. Similarly, other parameter value variations were based on calculations of Kerns method. The total number of design calculations with the data shown in the table 2 is 1080 , which is the number of training data available for the ANN routine.

The specific heat values and the thermal conductivity values were calculated with the following formulae given in Mansure and Speight, respectively. The correlations are given below,

$$
C_{p}=\frac{1}{\gamma}(0.4024-0.00081 \times T)
$$

where, $C_{p} C_{p}$ is the specific heat of oil, $\gamma \gamma$ is the specific gravity of the oil and $T T$ is the temperature in ${ }^{\circ} \mathrm{C}$

$$
k_{f}=\frac{1.62}{\gamma}(1-0.0003(T-32))
$$

where, $k_{f} k_{f}$ is the thermal conductivity of oil, $\gamma \gamma$ is the specific gravity of the oil and TT is the temperature in ${ }^{\circ} \mathrm{F}$

Table 2. Training data set design of experiments

\begin{tabular}{lll}
\hline Parameters & Data values & Units \\
\hline Tube flow velocity & $0.9,1.2,1.6,2,2.4$ & $\mathrm{~m} / \mathrm{s}$ \\
Tube thickness & $1.5,1.7,1.9,2.1,2.3,2.5$ & $\mathrm{X} 10^{-3} \mathrm{~m}$ \\
Ratio of baffle spacing to shell diameter & $0.15,0.2,0.25 .0 .3,0.35,0.4$ & --- \\
Ratio of tube pitch to tube outer diameter & $1.25,1.3,1.35,1.4,1.45,1.5$ & --- \\
\hline
\end{tabular}


DESIGN OF EXPERIMENTS PARAMETER

VALUE

\section{Kerns method of heat exchanger design}

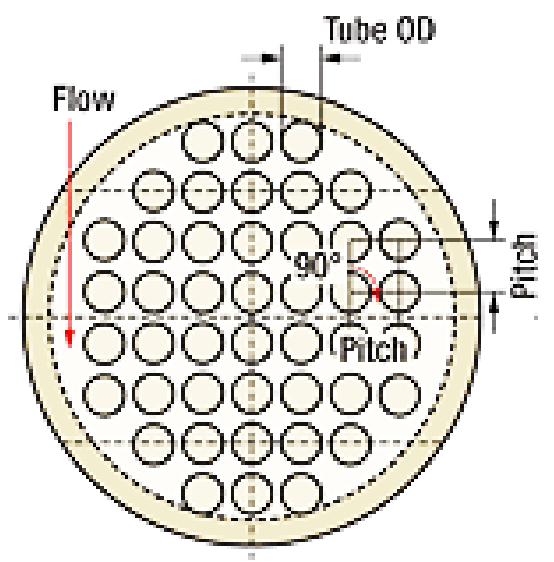

Figure 3. The cross section of a shell and tube heat exchanger showing the pitch, flow direction of the shell side fluid, and the tube pitch

In the shell and tube heat exchanger, it is better to reduce heat loss by passing the hot fluid through the tubes while the cold fluid absorbs heat on the shell side. Using the energy balance equation and the design heat duty we first verify the given data is recorded at steady state operation. The simple Kern's method of design of heat exchangers starts with the choice of the tubes. The inner or outer diameters and the thickness are first assumed and the number of tubes is fixed based on the designed mass flow rate and the velocity of the fluid flow in the tubes. Subsequently the tube side Reynolds number and Prandtl number is calculated.

$$
\begin{aligned}
& N_{t}=\frac{4 \times m_{t}}{\rho_{t} u_{t} \pi d_{i}^{2}} \\
& R e_{t}=\frac{\rho_{t} u_{t} d_{i}}{\mu_{t}} \\
& \operatorname{Pr}_{t}=\frac{v_{t}}{\alpha_{t}}
\end{aligned}
$$

From these calculations Nusselt number for the fluid flow inside the tube can be calculated using
Petukhov - kirillov correlations as shown below. The Reynolds number and Prandtl number range for these equations are $10^{4}<R e_{t} R e_{t}<5 \times 10^{6}$ and 0.5 $<P r_{t} P r_{t}<2000$.

$$
\begin{aligned}
& N u_{t}=\frac{\frac{f}{2} \cdot R e_{t} \cdot P r_{t}}{1.07+12.7 \cdot\left(\frac{f}{2}\right)^{\frac{1}{2}}\left(P r_{t}^{\frac{2}{3}}-1\right)} \\
& \text { where, } f=\left(1.58 \cdot \ln \left(R e_{t}\right)-3.28\right)^{-2} \\
& f=\left(1.58 \cdot \ln \left(R e_{t}\right)-3.28\right)^{-2}
\end{aligned}
$$

The heat transfer coefficient on the inside of the tube can be calculated using the Nusselt number.

$$
h_{t}=N u_{t} \frac{k_{f}}{d_{i}}
$$

Shell-side calculations can now begin by first finding the cross flow equivalent diameter (hydraulic diameter) at the diameter of the shell. The equivalent diameter is given by:

$$
D_{e}=4 \frac{\text { Netfreeflowarea }}{\text { heattransferperimeter }}
$$

For triangular arrangement of tubes the equivalent diameter is given by

$$
D_{e-\text { triangular }}=\frac{4 \cdot A_{\text {flow }}}{P_{\theta}}
$$

Using the equivalent diameter we can calculate the Reynolds number on the shell-side fluid flow as shown below 


$$
\begin{aligned}
& R e_{s}=\frac{\rho_{s} U_{s} D_{e}}{\mu_{s}} \\
& R e_{s}=\frac{\dot{m}_{s}}{A_{s}} \times \frac{D_{\theta}}{\mu_{s}}
\end{aligned}
$$

The shell-side area perpendicular to the fluid flow (area of heat transfer) can be calculated using following steps. First, the projected area of the tubes is calculated, and the total area of the shell is found by accounting for the number of tube in the design. And finally the total shell side heat transfer is calculated using the shell diameter. The ratio of baffle spacing and the shell diameter is used for convenience to calculate the area of shell-side heat transfer area.

$$
A_{\text {projected }}=C L \times P_{T}^{2}
$$

where, $C L=0.87 C L=0.87$ for triangular arrangement of tubes.

$$
A_{\text {shell }}=\frac{N_{t} A_{\text {projected }}}{C T P}=\frac{\pi}{4} D_{s}{ }^{2}
$$

where, $\mathrm{CTP}=0.9$ for two tube passes in shell.

$$
A_{s}=\frac{D_{s}}{P_{t}} \cdot C \cdot B
$$

where, the ratio of baffle spacing to the shell diameter is one of the parameters to the input to the design.

The outer heat transfer coefficient can be calculated using the Nusselt number correlation for Reynolds number and Prandtl number.

$$
h_{0}=\frac{0.36 k_{s}}{D_{s}} \operatorname{Re}_{s}^{0.55} \mathrm{Pr}_{s}^{0.33} \quad\left(2 \times 10^{3}<R e_{s}<1 \times 10^{6}\right)
$$

The overall heat transfer coefficient is then calculated as shown below
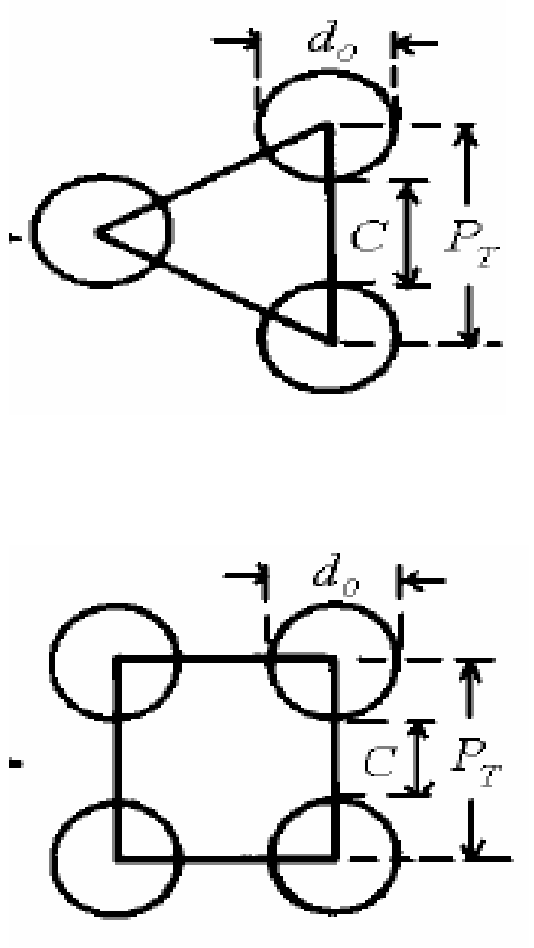

Figure 4. The configuration of tubes in the shell and tube heat exchanger

$\frac{1}{U}=\frac{1}{h_{o}}+\frac{1}{h_{i}} \times \frac{d_{0}}{d_{i}}+\frac{r_{o} \ln \frac{r_{0}}{r_{i}}}{k}$

In the above equation, the heat transfer resistance due to fouling factor is not accounted. This can be accounted in the equation shown below:

$\frac{1}{U_{f}}=\frac{1}{U}+R_{f}$

Using the overall heat transfer coefficient, the area of the heat transfer in the heat exchanger is calculated by the LMTD and the heat duty of the heat exchanger.

$$
A_{f}=\frac{Q_{\text {heatduty }}}{U_{f} \times L M T D}
$$

The log mean temperature difference (LMTD) is given by: 


$$
L M T D=\frac{\Delta T_{1}-\Delta T_{2}}{\ln \left(\Delta T_{1} / \Delta T_{2}\right)}
$$

where, $\Delta T_{1}=T_{h, \text { in }}-T_{c, \text { out }} \Delta T_{1}=T_{h, \text { in }}-T_{c, \text { out }} \quad$ and $\Delta T_{2}=T_{h, \text { out }}-T_{c, \text { in }} \Delta T_{2}=T_{h, \text { out }}-T_{c, \text { in }}$

The length of the heat exchanger can be calculated from the heat transfer area by:

$$
L=\frac{A_{f}}{N_{\text {tubepass }} \cdot \pi d_{o}}
$$

The tube side pressure drop is

$$
\begin{aligned}
& \Delta P_{t}=\left(4 f_{t} \frac{L N_{t}}{d_{i}}+4 N_{t}\right) \frac{\rho_{t} \cdot u_{t}^{2}}{2} \\
& f_{t}=\left[1.58 R e_{t}-3.25\right]^{-2}
\end{aligned}
$$

The shell side pressure drop is calculated by

$$
\begin{aligned}
& \Delta P_{s}=\frac{f_{s} G_{s}^{2}\left(N_{B}+1\right) D_{s}}{2 \rho_{s} D_{\theta} \mu_{s}} \\
& f_{s}=\exp \left(0.576-0.19 \ln R e_{s}\right) \\
& \mu_{s}=\frac{\mu}{\mu_{w}}
\end{aligned}
$$

where, $\mu_{w} \mu_{w}$ is the viscosity of the fluid at the wall temperature $T_{w} T_{w}$. The wall temperature is calculated by

$$
T_{w}=\frac{1}{2} \times\left(\frac{T_{h, \text { in }}-T_{h, \text { out }}}{2}+\frac{T_{c, \text { in }}-T_{c, \text { out }}}{2}\right)
$$

\section{Dynamic behavior of heat exchangers}

The shell and tube heat exchangers undergo temperature variations in their routine operations. These temperature variations could be a simple step rise or fall or can be more complex temperature function with time. In particular, a simple mathematical model is developed and coded in Libre Office Calcworksheet to describe the temperature at various points in the heat exchanger. The conduction in the direction of fluid flow is neglected and the tube is divided into several segments. And the individual segments are modeled using the equations shown below.

$$
m_{i} H_{i}+m_{i+1} H_{i+1}=\frac{C_{p} \Delta T}{d T}+\dot{Q}
$$

$\mathrm{A} \Delta T \Delta T$ of $5 \mathrm{deg} \mathrm{C}$ step rise in the hot fluid is assumed and the model predicts the temperature rise to move as a wave from the inlet to outlet side as shown in the graph below. It can be seen that the step takes about 240 seconds to reach the outlet side. Figure 5 a shows the temperature variation in the cold fluid side. The cold fluid side does not show the temperature wave instead gradually increases in temperature with time as can be observed in figure $5 \mathrm{~b}$. The rise in temperature takes approximately 240 minutes to reach from inlet to outlet on the hot fluid. But the sudden jump in temperature behavior is not clearly shown on the cold side because of higher turbulence and mixing of fluids. 


\section{Transient response of hot fluid}
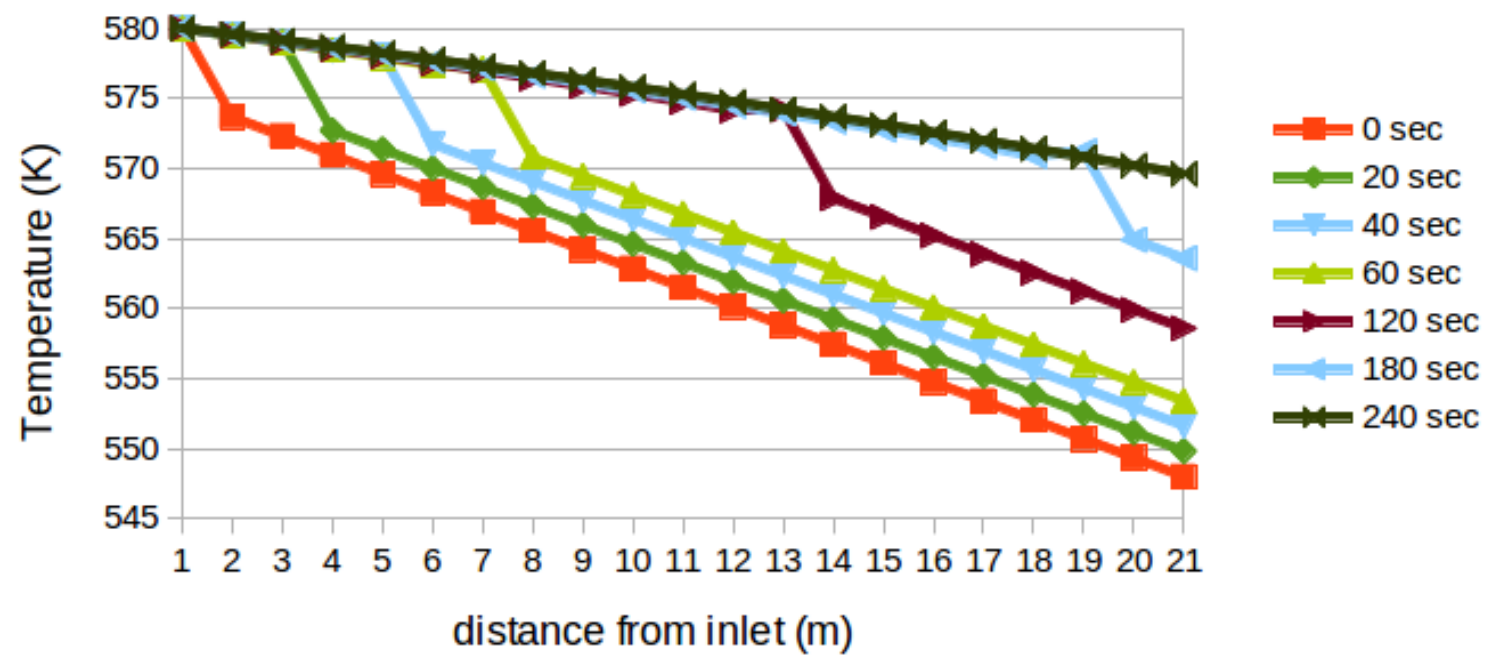

Figure 5a. Transient behavior on the tube side fluid

\section{Transient response of cold fluid}
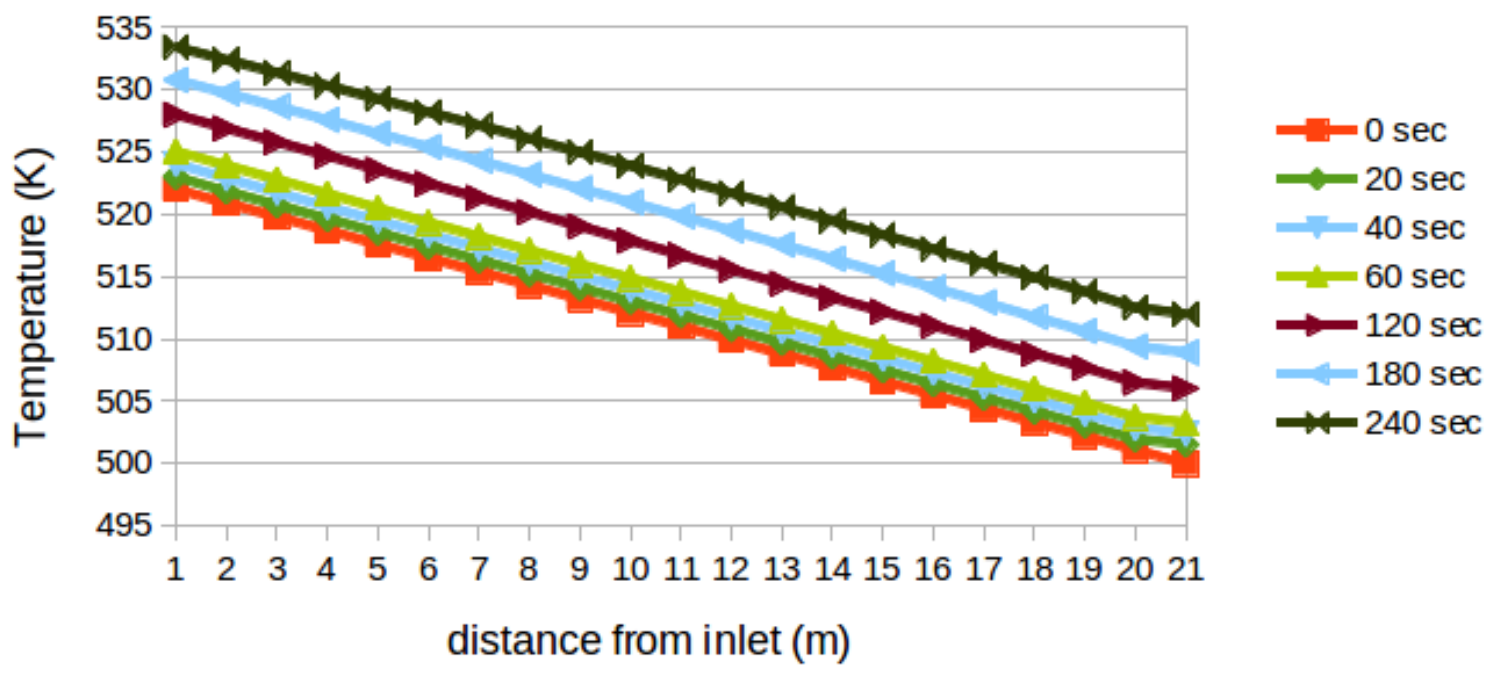

Figure 5b. Transient behavior on the shell side fluid 


\section{Overall Heat transfer}

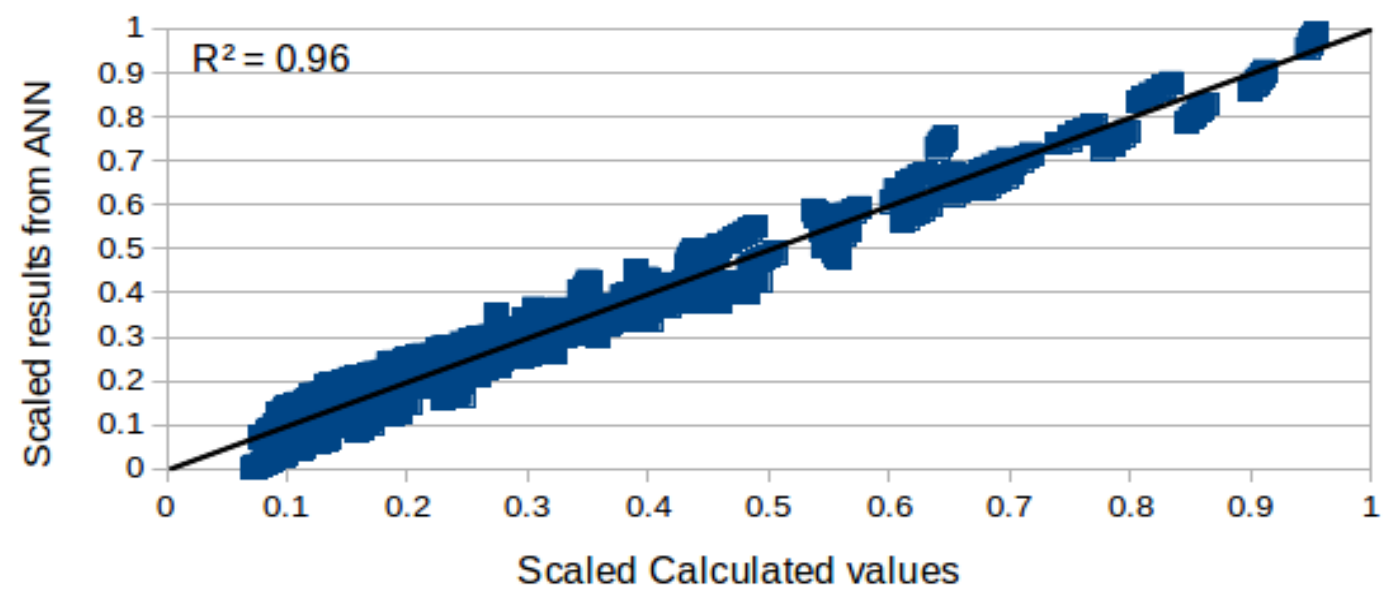

Figure 5c. Overall heat transfer coefficient comparison between ANN prediction and Kern's method value

\section{Shell side pressure drop}

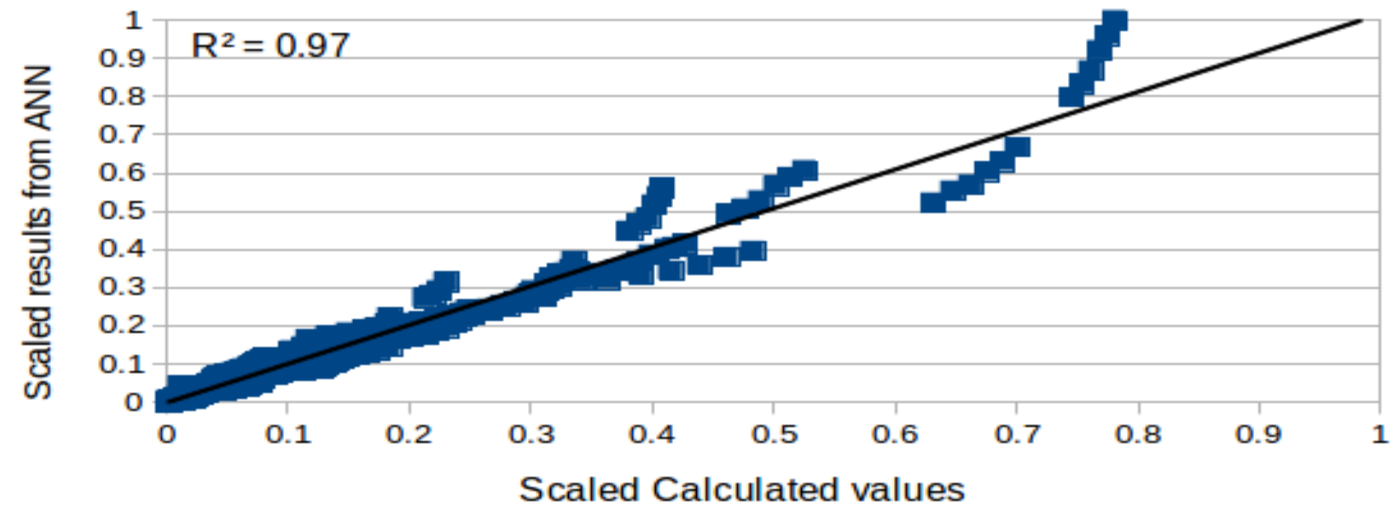

Figure 5d. Shell side pressure drop comparison between ANN prediction and Kern's method value

\section{Tube side pressure drop}

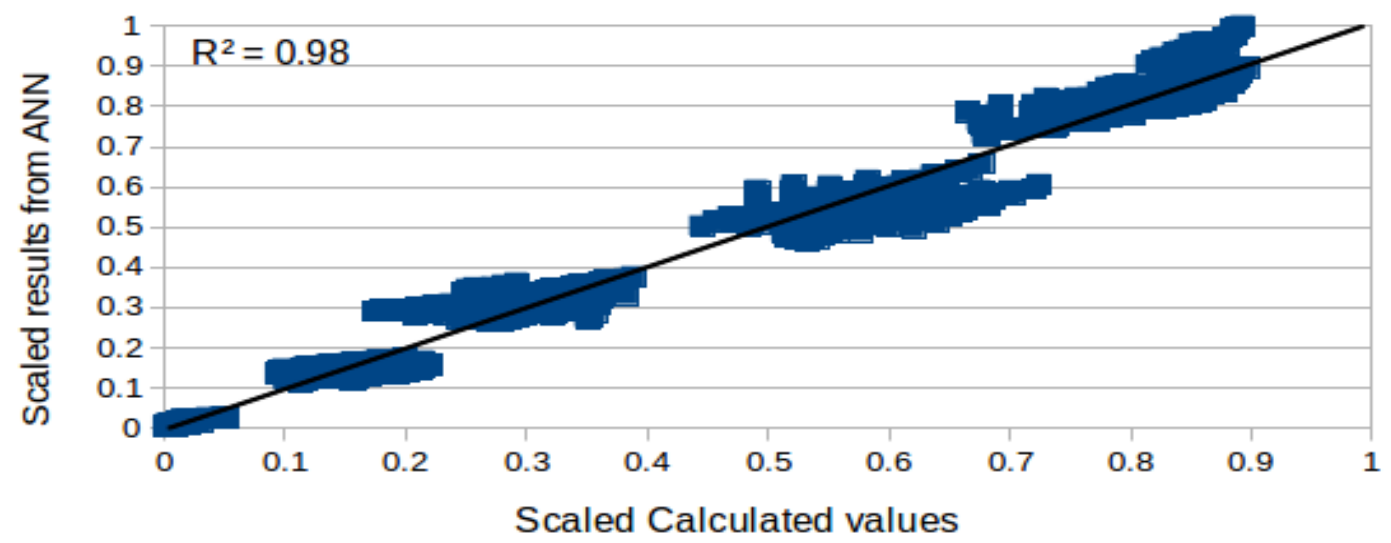

Figure 5e. Tube side pressure drop comparison between ANN prediction and Kern's method value 


\section{RESULTS AND CONCLUSIONS}

Heat exchanger design consists of both thermal and structural (vibrational) design and testing. Computational fluid dynamic simulation is used to find the flow structures, major and minor losses in the heat exchanger, along with the heat transfer coefficients and the pressure drop across the tubes and that for the shell. CFD simulation of shell and tube heat exchangers is very cumbersome and needs high power computing facilities. The motivation for this research is to find the suitability of artificial neural networks in estimation of heat transfer coefficient, tube side and shell side pressure drop. Since Feed forward Neural Networks can easily accommodate a large input and output parameters with sufficient training data, additional input and output parameters can be easily incorporated. These quantities are calculated by experimental correlations, and are best suited for ANN estimation. With the current ANN calculations, the values of heat-exchanger heat transfer coefficient, pressure drop in tube and shell can be estimated rapidly. This method speeds up the thermal design iteration and in particular best thermal designs can be selected from a large number of preliminary trial and error designs.

Results from the ANN simulation prediction is shown in figure $5 \mathrm{c}, 5 \mathrm{~d}$, and $5 \mathrm{e}$. It can be observed from figure $5 c$ that the overall heat transfer coefficient prediction is close, with $\mathrm{R}^{2}$ value of 0.96 . All the predicted points are equally spaced, and the chosen data values in design of experiments are well suited for the overall heat transfer ANN prediction. The shell side pressure drop ANN prediction is compared with Kern's method calculations in Figure 5d. At higher pressure drops, ANN over predicts the pressure drop. Also the prediction values are clumped together and further study is necessary. Figure 5e, is the pressure drop prediction on the tube side. The plot has evenly distributed values in the lower set of pressure drop while there are data points forming groups; this shows that the input parameter combination (velocity, tube diameter, tube pitch and baffle spacing) needs to be closely spaced for future ANN calculations. But just based on the $\mathrm{R} 2$ values for the figure $5 \mathrm{c}, 5 \mathrm{~d}$, and $5 \mathrm{e}$ it can be safely said that the ANN predictions are acceptable and further improvements should include more number of input variables, and closely spaced design of experiment values for these inputs. Alternate neural network methods such as unsupervised methods can also be used in the future.

Temperature versus the heat exchanger length during the step increase in the inlet temperature is shown in the Figure $4 \mathrm{a}$ and $4 \mathrm{~b}$. This dynamic behavior plots shows a marked difference between the shell side shown in figure $4 \mathrm{~b}$ and the tube side (Figure $4 \mathrm{a}$ ). The step increase of $5^{\circ} \mathrm{C}$ in temperature at the tube inlet shows up as step in progressive fluid flow direction in consecutive iterations. This thermal behavior of tube side fluid is expected since the flow tubes have a lower heat transfer coefficient compared to that on the shell side. The shell side fluid does not show the step increase in the temperature because of higher heat transfer coefficient and in a shell and tube heat exchanger, the flow of fluid is a combination of cross flow and counter flow direction. The shell side fluid temperature rises evenly and reaches the maximum increase of about $4.5^{\circ} \mathrm{C}$.

\section{REFERENCES}

Costaa, A. L. H and Queiroz, E.M. (2008). Design optimization of shell-and-tube heat exchangers. Applied Thermal Engineering 28:1798-1805.

Duran, O., Nibaldo, R and Luis, A. C. (2008). Neural Networks for Cost Estimation of Shell and Tube Heat Exchangers.'In Proceedings of the International Multi-Conference of Engineers and Computer Scientists, Hong Kong.

Gerardo, D., Sen, M., Yang, K.T and McClain.R.L., (2001). Dynamic prediction and control of heat exchangers using artificial neural networks. International Journal of Heat and Mass Transfer 44: 1671-1679. 
Gerardo, D., Sen, M., Yang, K.T and McClain, R. L. (1999). Simulation of heat exchanger performance by artificial neural networks. HVAC and Refrigeration Research 5(3): 195-208.

Gvozdenac, D and Mitrovic, J. (2012). Analytical Solution of Dynamic Response of Heat Exchanger, in Heat Exchangers - Basics Design Applications, In Tech, DOI: 10.5772/35944.

Jalili-Kharaajoo, M and Araabi, B. N. (2004). Neural network based predictive control of a heat exchanger nonlinear process. Journal of Electrical and Electronics Engineering 4:1219-1226.

Jaluria, Y. (2007). Design Optimization of Thermal Systems, CRC Press.

Kakac, S and Liu, H. (2012). Heat Exchangers Selection, Rating, and Thermal Design, CRC Press.

Mansure, A. J. (1996). Hot Oiling Spreadsheet, Sandia National Laboratory Report, SAND96-2247 UC122 ,

Pacheco-Vega, .A., Diaz, G., Sen, M., Yang, K.T and McClain, R.L. (2001). Heat rate predictions in humid air-water heat exchangers using correlations and neural networks. Journal of Heat Transfer 123: 348-354.

Ponce-Ortega, J. M., Serna-González, M and Jiménez-Gutiérrez, A. (2009). Use of genetic algorithms for the optimal design of shelland-tube heat exchangers. Applied Thermal Engineering 29: 203-209.

Rajiv, M. (1998). Effectively Design Shell-andtube Heat Exchangers. Chemical Engineering Process.

Riverol, C and Napolitano, V. (2005). Estimation of fouling in a plate heat exchanger through the application of neural networks. Journal of Chemical Technology and Biotechnology 80:594-600.
Selbaş, R., Kiilkana, O and Reppich, M. (2006). A new design approach for shell-and-tube heat exchangers using genetic algorithms from economic point of view. Chemical Engineering and Processing: Process Intensification 45 : 268-275.

Skrjanc, I and Drago, M. (2000). Predictive functional control based on fuzzy model for heat exchanger pilot plant. IEEE Transactions on Fuzzy Systems 8(6):705-712.

Speight, J. G. (2006). The Chemistry and Technology of Petroleum. CRC Press.

Tan, C.K., Ward, J., Wilcox S. J and Payne R. (2009). Artificial neural network modeling of the thermal performance of a compact heat exchanger. Applied Thermal Engineering 29: 3447-3722.

Vasičkaninová, A., Bakošová, M., Mészáros, A and Klemeš, J. J. (2011). Neural network predictive control of a heat exchanger. Applied Thermal Engineering. doi: 10.1016/j. applthermaleng.2011.01.026.

Wolff, E. A., Mathisen, K. W and Skogestad, S. (1991). Dynamics and Controllability of Heat Exchanger Networks. Proceedings of COPE, Barcelona, Spain. 
NOMENCLATURE

$C_{p} \quad$ Specific heat at constant pressure $\mathrm{kJ} / \mathrm{kg} \mathrm{K}$ $\mathrm{kJ} / \mathrm{kgK}$

$\gamma \quad$ Specific gravity

$T \quad$ Temperature

$k_{f} \quad$ Thermal conductivity of fluid $\mathrm{W} / \mathrm{mK}$

$N_{t} \quad$ Number of tubes

$m_{t} \quad$ tube side mass flow rate

$u \quad$ velocity of fluid $\mathrm{m} / \mathrm{s}$

$\begin{array}{ll}\rho & \text { density } \\ & \mathrm{kg} / \mathrm{m}^{3} \\ d & \text { tube diameter } \mathrm{m}\end{array}$

Re Reynolds number

$\mathrm{Pr} \quad$ Prandtl number

$\mathrm{Nu} \quad$ Nusselt number

$f \quad$ friction factor

$\mu \quad$ dynamic viscosity centi poise

$v \quad$ kinematic viscosity $\mathrm{m}^{2} / \mathrm{s}$

$\alpha \quad$ thermal diffusivity $\mathrm{m}^{2} / \mathrm{s}$

$h$ heat transfer coefficient $W / m^{2} \mathrm{~K}$

$D$ shell diameter $m$

$\mathrm{P}$ Pressure $\mathrm{Pa}$

$A_{\text {flow }}$ flow area $\mathrm{m}^{2}$

$C L \quad$ clearance length

CTP connected tube passes

$A_{\text {projected }} \quad$ Projected area on shell side as seen by the flowing fluid $\mathrm{m}^{2}$

$A_{\text {shell }}$ Total shell area $\mathrm{m}^{2}$

$U \quad$ overall heat transfer coefficient $W / \mathrm{m}^{2} \mathrm{~K}$

$\triangle P \quad$ pressure drop $P a$

$G$ mass flow rate $\mathrm{kg} / \mathrm{s}$

$\mathrm{H}$ enthalpy of fluid $\mathrm{kJ} / \mathrm{kg} \mathrm{K}$
Subscripts

$t$ tube

$s \quad$ shell

h hot fluid side

c cold fluid side

in inlet

out outlet

w wall properties

$i, i+1$ indices for discrete numerical equation 